\title{
SPIGELIAN HERNIA : A DIAGNOSTIC DILEMMA
}

\section{General Surgery}

\section{Dr. Shailendra Rai}

Junior Resident, Department Of General surgery, Institute of Medical sciences, Banaras Hindu University, Varanasi, India

\section{Dr. Basanti Mazumdar*}

\section{Dr. Arvind Pratap}

Junior Resident, Department Of General surgery, Institute of Medical sciences, Banaras Hindu University, Varanasi, India *Corresponding Author

Assistant Professor, Department Of General surgery, Institute of Medical sciences, Banaras Hindu University, Varanasi, India

\section{ABSTRACT}

PURPOSE- Spigelian Hernia[SH] constitutes $0.12 \%$ to $2 \%$ of total abdominal wall hernia. The diagnosis of SH poses great difficulty because of non-specific presentation, and non obvious finding on examination. Also, Surgeons are less experienced with this entity and have low index of suspicion further contributing to underdiagnosis. Thus, whether SH is a rare entity or an underdiagnosed condition is debatable. The aim is share our experience and discuss different clinical aspects and outcomes of SH with a literature review regarding diagnostic difficulties.

PATIENTS AND METHODS- This is a case series of 18 patients diagnosed with $20 \mathrm{SH}$, were operated in a single surgical unit of Sir Sunderlal Hospital from January 2016 to July 2019. Historical patient's records including demographic profiles, clinical presentation, and management were analysed.

RESULTS- Total 18 patients were admitted with women preponderance. The mean age of presentation was 39.23years. The most common presentation is pain followed by swelling. Most patients don't have any clinical finding. Defect is identified only in 3 patients. Ultrasound, ContrastEnhanced Computed Tomography and Magnetic Resonance Imaging were used to diagnose the hernia. All the patients were managed operatively with pre-peritoneal fat as the most frequent content.

CONCLUSION- SH is a diagnostic challenge with rather simple management. A high index of clinical suspicion is the key to diagnosis. SH seems more of an under-diagnosed rather than a rare entity. Also the author suggests to scan whole length of spigelian aponeurosis whenever there is a suspicion or the failure to reach an otherwise diagnosis.

\section{KEYWORDS}

Spigelian Hernia, Under-Diagnosed, Rare, Ultrasound, Surgery.

\section{INTRODUCTION-}

Spigelian Hernia $[\mathrm{SH}]$ otherwise known as hernia of semilunar line or spontaneous lateral ventral hernia constitutes $0.12 \%$ to $2 \%$ of all the abdominal wall hernias. It is a small interparietal hernia $[1,2]$. It can develop anywhere along the linea semilunaris, the lateral border of rectus sheath. The most common location is spigelian point. This point is the widest and thus weakest, represents the junction of linea semilunaris and linea semicircularis, at a level below the umbilicus. In about $90 \%$ patients' defect is identified at this point [3]. We here by present our experience of 18 cases with $20 \mathrm{SH}$ with varied presentations and outcomes. The diagnosis of SH poses great difficulty because of non-specific presentation, and non obvious swelling on examination as it is intra parietal nature, and SH is usually overlooked because it is masked under intact external aponeurosis and subcutaneous fat. Small SH donot exhibit the characteristics of other hernias. All these factors contribute to rarity of SH. Thus, surgeons are less experienced with this entity and have low index of suspicion further contributing to underdiagnosis. Thus, whether $\mathrm{SH}$ is, a rare entity or an under-diagnosed condition, is debatable. Through this study we aim to share our experience and discuss different clinical aspects and outcomes of $\mathrm{SH}$ with a literature review regarding diagnostic difficulties.

\section{PATIENTS AND METHODS-}

This is a case series of 18 patients diagnosed with $20 \mathrm{SH}$ and were operated after taking informed consent in a single surgical unit of Sir Sunderlal Hospital [SSH] from January 2016 to July 2019. Historical patient's records including demographic profiles, clinical presentation, and management were analysed.

\section{RESULTS}

A total of 18 patients were admitted with women preponderance. The mean age of presentation was 39.23 years [12-84years]. Out of 18 , only 4 patients were more than 60 years of age. Right sided predominance was observed [TABLE 1]. The commonest presentation was isolated flank pain followed by swelling in the flank. Other non specific presentations were enumerated in table number 2.
Table 1-Showing The Characteristics Of Patients.

\begin{tabular}{|c|c|c|c|}
\hline S. No. & & Patients & Percentage [\%] \\
\hline \multirow[t]{2}{*}{1} & Gentleman & 6 & 33.34 \\
\hline & Lady & 12 & 66.67 \\
\hline \multirow[t]{2}{*}{2} & $<60$ years of age & 14 & 77.78 \\
\hline & $>60$ years of age & 4 & 22.23 \\
\hline \multirow[t]{3}{*}{3} & Right sided SH & 12 & 66.67 \\
\hline & Left sided SH & 4 & 22.23 \\
\hline & Bilateral SH & 2 & 11.12 \\
\hline
\end{tabular}

Table 2-Depicting The Symptoms.

\begin{tabular}{|l|l|l|l|}
\hline S. No. & Symptoms & Patients & Percentage [\%] \\
\hline 1 & Flank Pain & 9 & 50 \\
\hline 2 & Swelling in flank & 4 & 22.23 \\
\hline 3 & Swelling ass with pain & 1 & 5.56 \\
\hline 4 & Pain ass with vomiting & 1 & 5.56 \\
\hline 5 & $\begin{array}{l}\text { Pain, vomiting and non passage } \\
\text { of stool and flatus }\end{array}$ & 1 & 5.56 \\
\hline 6 & $\begin{array}{l}\text { Flank pain and inguinoscrotal } \\
\text { swelling }\end{array}$ & 1 & 5.56 \\
\hline 7 & $\begin{array}{l}\text { Swelling in bilateral flanks and } \\
\text { inguinoscrotal }\end{array}$ & 1 & 5.56 \\
\hline
\end{tabular}

The local examination was unremarkable in [TABLE 3] in 7 cases $[35 \%]$, tenderness was the only finding in another 5 cases. A total of 8 patients had clinically appreciable swelling [figure $1 \mathrm{a} \& 1 \mathrm{~b}$ shows 65 years male patient with swelling in bilateral iliac region] and reduciblity along with cough impulse could be demonstrated in three of them with apparent defect. Single patient had associated bilateral inguinal hernia and another patient had bilateral hydrocele.

Table 3-Clinical Finding On Examination

\begin{tabular}{|l|l|l|l|}
\hline S. No. & Clinical finding on examination & No. of SH & Percentage [\%] \\
\hline
\end{tabular}

\begin{tabular}{|l|l|l|l|}
\hline 1 & Un-remarkable & 7 & 35 \\
\hline 2 & Tenderness & 6 & 30 \\
\hline 3 & Apparent swelling & 8 & 40 \\
\hline 4 & Defect & 3 & 15 \\
\hline 5 & Cough impulse & 3 & 15 \\
\hline
\end{tabular}


Ultrasound [USG] was done in all the patients and was diagnostic in 10 SH. Figure 2 shows the USG finding of a patient with bilateral SH, suggesting lower anterior abdominal wall defect on both sides [right$3.4 \times 2.9 \mathrm{~cm}$, left $-1.04 \times 1 \mathrm{~cm}$ ], with herniation of bowel loop as content. Although Contrast-enhanced computed tomography [CECT] was done in the remaining and was found to be diagnostic in 9 out of 10 cases, magnetic resonance imaging [MRI] was performed in a single patient as USG and CECT were unfruitful in establishing the diagnosis[figure 3]. Defect was identified in all the cases. Besides SH, 1 patient had left ovarian cyst, 1 had cholelithiasis, 1 had bilateral hydrocele and another had bilateral inguinal hernia. Pre-peritoneal fat is the most common content, demonstrated in 55\% SH [TABLE 4] followed by omentum in $30 \%$, bowel in $10 \%$ and caecum and ileocaecal region [ICR] in a single patient.

Table 4-Showing The Intra-operative Finding Of Sh.

\begin{tabular}{|l|l|l|l|}
\hline S. No. & Content of SH & No. of SH & Percentage [\%] \\
\hline 1 & Pre-peritoneal fat & 11 & 55 \\
\hline 2 & Omentum & 6 & 30 \\
\hline 3 & Bowel & 2 & 10 \\
\hline 4 & Caecum and ICR & 1 & 5 \\
\hline
\end{tabular}

All the patients were managed operatively. Pre-peritoneal mesh hernioplasty was performed in 16 patients [figure $4 \mathrm{a} \& 4 \mathrm{~b}$ ]. Additional procedures like Laparoscopic Cholecystectomy in 1 patient, Laparoscopic excision of left ovarian cyst in 1 and bilateral Eversion of sac in 1 patient, were done in the same sitting. Onlay mesh hernioplasty was done in 2 patients, one of them was diagnosed with bilateral $\mathrm{SH}$ with bilateral inguinal hernia and another with obstructed right $\mathrm{SH}$. The mean duration of hospital stay was 1.94 days [1-6days]. None of them developed any complication or recurrence over a period of 6 month [figure 5].

\section{DISCUSSION-}

SH also called Hernia Spigeli, is a rare entity. This hernia can be congenital or acquired, occurring commonly in the Spigelian belt [1]. Many of the previous studies concluded that the common age of presentation to be more than 60years [4] but our study demonstrates a conflicting result with majority of patient below the age of 60 . But has similar sex predilection demonstrated by others with women:men ratio of 2: $1[4,5]$. The predominance of younger age group in our study is attributable to the advances in diagnostic modalities and increasing awareness, thus identifying the obscured hernia without much delay, which would have gone undiagnosed previously.

Most patients presented with pain, owing to its narrow neck which also predisposes them to obstruction. The majority of SH don't have the characteristic presentation of hernia [1] thus hindering the diagnosis. But they can undergo obstructive changes due to the narrow neck [5, 6]. Incarceration is present in $10-24 \%$ of SH [7].

The differential diagnosis of painful swellings or chronic painful conditions of the abdominal wall includes Spigelian hernia, rectus sheath hematoma, abdominal wall endometriosis, a skin cyst, abdominal wall nerve entrapment syndrome. These conditions can be differentiated easily with the help of USG. Abdominal wall nerve entrapment syndrome mimics SH by its location.

Patients may frequently present with small, non-reducible swelling thus mimicking hematoma and lipoma. Frequently SH undergoes unnoticed and thus is not reported [4]. Obesity also impedes the diagnosis. All these factors result in underdiagnosis of this hernia. SH at the level below the umbilicus, can also be confused with inguinal hernia. A study conducted in 2001 reported strangulated SH mimicking diverticulitis [8].

Only a few patients in our study have clinically demonstable defect and/or cough impulse, which is generally considered as the characteristic features of hernia. Long-standing SH may access the external aponeurosis, becoming comparatively prominent [5]. Thus one needs a high index of suspicion and expert hands to diagnose $\mathrm{SH}$.

Preperitoneal fat was the content in 55\% of SH. A previous study conducted on spigelian hernia in 2018 found omentum as the most common content of hernia [6]. Although very uncommon, caecum and ICR were found to be content in a single patient in our study. There are case reports showing $\mathrm{SH}$ with caecum as content $[7,9]$.
USG is recommended as the preferred imaging modality to diagnose $\mathrm{SH}[10]$ and now used as an extension of clinical examination. It also requires experienced radiologists to minimize false-negative results. Half the SH in our study was diagnosed with USG. The real-time USG can help in imaging in supine as well as standing position, with or without Valsalva, thus can help in diagnosing obscured SH. But the main disadvantage is operator dependency. In our study group, other ultrasonographic findings were very variable, and included? cystitis, ?appendicitis, ?enterocolitis, ?mesenteric adenitis, focal inflammatory changes, ?texiloma and normal study.

CT comes into play when USG is non-diagnostic or equivocal. CT scan is recommended as the diagnostic modality of choice [11]. CT has better sensitivity and specificity than USG in diagnosing SH. CT aids in localizing the defect and identify the content thus helps the surgeon in better Pre-operative planning [12]. MRI is recommended when there is a high index of suspicion but USG and CT fails to demonstrate $\mathrm{SH}$. MRI, due to its caliber of soft tissue differentiation can identify this inter-parietal hernia with small defect size.

$\mathrm{SH}$, although is uncommon, should be treated surgically whenever encountered due to its high probability of strangulation, attributed to its narrow neck [13]. A study conducted on 3 cases of SH concluded that even the incidentally found SH should be treated surgically whenever possible [14]. We approached all these patients with open surgical techniques, with mean operating time of $83 \mathrm{~min}$ [45min to $135 \mathrm{~min}]$. Although Herniorrhaphy and Hernioplasty both were employed in treating $\mathrm{SH}$ in past, some authors preferred usage of prosthesis to reduce the incidence of incisional hernia [15]. Laparoscopic techniques also evolved to address SH like Totally extraperitoneal laparoscopic Spigelian hernia repair [TEP] [16, 17], Intraperitoneal Onlay Mesh repair [IPOM] [13] and Transabdominal Preperitoneal repair [18]. A modification of IPOM popular as Scroll technique, is a much easier approach, and involves less intraperitoneal mesh handing, has higher success rates, and lower recurrence rates than IPOM [19].

\section{CONCLUSION-}

$\mathrm{SH}$ is a diagnostic challenge with rather simple management. A high index of clinical suspicion is the key to diagnosis. SH seems more of an under-diagnosed rather than a rare entity. Also the author suggests to image whole length of spigelian aponeurosis whenever there is a suspicion or the failure to reach an otherwise diagnosis.

\section{DECLARATIONS-}

Funding-The study is self-funded.

Conflicts of Interest- The author declares no conflicts of interest.

Availability of data or material- All the data were collected from our hospital records.

Fig. 1a \& 1b- showing 65years male patient with swelling in bilateral iliac region

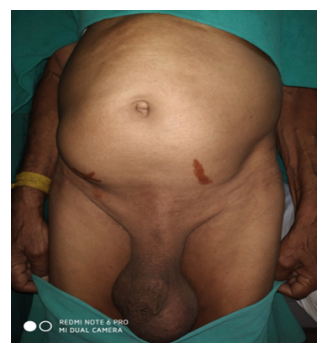

Fig. 1a

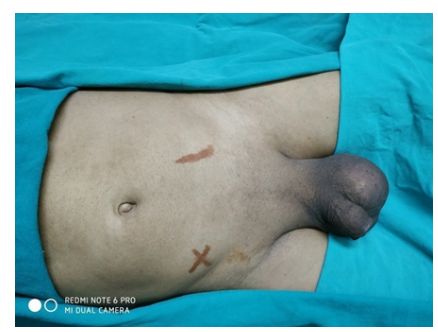

Fig. 1b 
Figure 2- USG showing defect in lower abdominal wall in both sides and bowel as content.

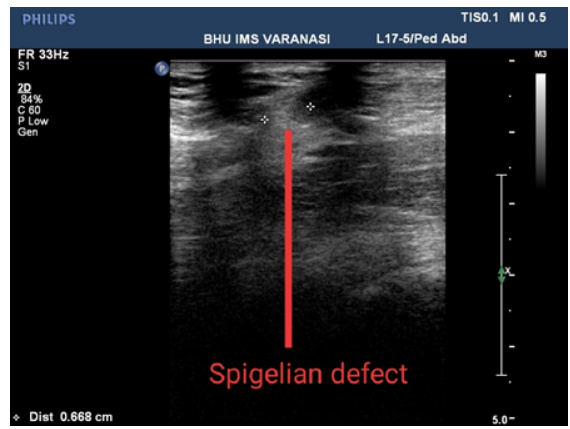

Figure 3- MRI of abdomen showing bilateral spigelian hernia

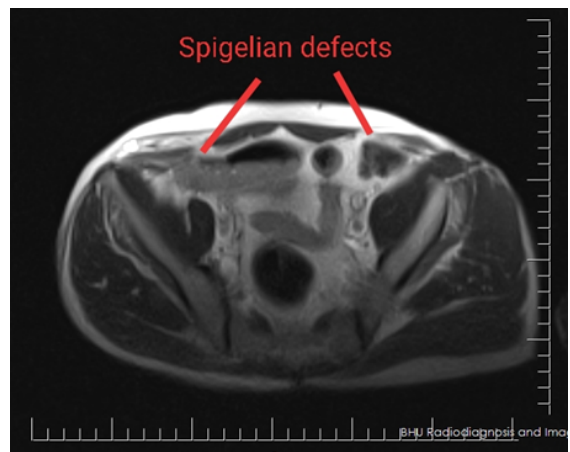

Figure 4a \& 4b showing intra-operative images

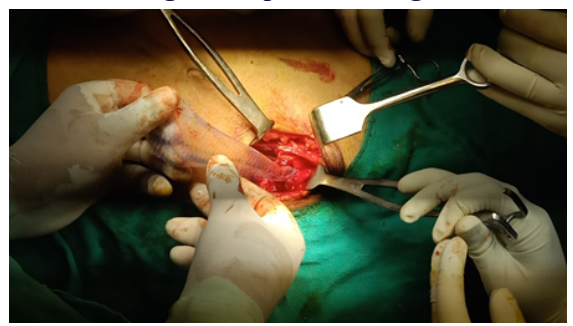

Figure 4a

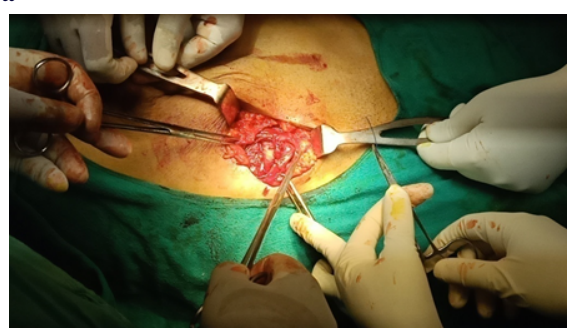

Figure 4b

Figure 5-post operative image of patient

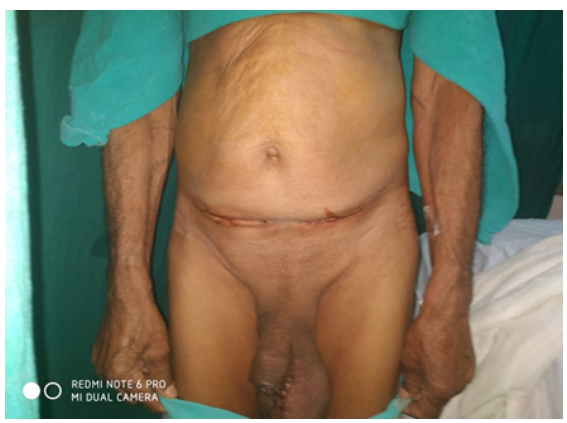

\section{REFERENCES-}

1. T Mittal et al (2008) Diagnosis and management of Spigelian hernia: A review of literature and our experience. J Minim Access Surg 4(4): 95-98

2. Griffin AS, Schaefer NR, Jeyarajan E, Cross T (2015) Concurrent Spigelian hernia and falciform ligament hernia in a 67 -year-old female. International Journal of Surgery Case Reports 13:27-29. https://doi.org/10.1016/j.ijscr.2015.05.035
3. Zinner M, Ashley S, Hines O (2019). Maingot's Abdominal Operations. Mc Graw Hill Education. 13th edn. United States, pp 223-224.

4. Larson DW, Farley DR (2002) Spigelian hernias: repair and outcome for 81 patients. World J Surg 26(10):1277.1281. https://doi.org/10.1007/s00268-002-6605-0

5. Olson RO, Davis WC (1968) Spigelian hernia: Rare or obscure? The American Journal of Surgery 116(6): 842-846. https://doi.org/10.1016/0002-9610(68)90453-4

6. Igwe PO, Ibrahim NA (2018) Strangulated sliding spigelian hernia: A case report International Journal of Surgery Case Reports 53: 475-478. https://doi.org/10.1016/j.ijscr.2018.10.043

7. Bashir MU et al (2016) Large Spigelian Hernia: Case Report and Review of Literature. Clinics in Surgery Volume 1 |Article 1124

8. Rogers FB, Camp PC (2001) A strangulated Spigelian hernia mimicking diverticulitis. Hernia 5(1):51.52. https://doi.org/10.1007/BF01576167

9. Dominika Karkocha et al (2019) Left-sided Spigelian Hernia With Nontypical Hernial Sac Content. Pol Przegl Chir 91(6):47-49. https://doi.org/ 10.5604/01.3001.0013.1995.

Spagen L (1989) Spigelian hernia. World J Surg 13:573-80

11. Campos SM, Walden T (1997) Figures in clinical medicine: Spigelian hernia. N Engl J Med 336:1149.

12. Martell EG, Singh NN, Zagorski SM, Sawyer MA (2004) Laparoscopic repair of a Spigelian hernia: a case report and literature review. J Soc of Laparoendosc Surg 8(3):269-274

13. Skouras C, Purkayastha S, Jiao L, Tekkis P, Darzi A, Zacharakis E (2011) Laparoscopic management of Spigelian hernias. Surg Laparosc Endosc Percutan Tech 21(2):76-81. https://doi.org/10.1097/SLE.0b013e31820d66df.

14. Khanjan H, Nagarsheth et al (2011) Laparoscopic Repair of Incidentally Found Spigelian Hernia. JSLS 15(1): 81-85

15. Skandalakis PN, Zoras O, Skandalakis JE, Mirilas P (2006) Spigelian hernia: surgical anatomy, embryology, and technique of repair. Am Surg 72(1):42-48

16. Tarnoff M, Rosen M, Brody F (2002) Planned totally extraperitoneal laparoscopic Spigelian hernia repair. Surg Endosc 16(2):359

17. Chan JW, Chiu PW, Ng EK (2008) Simultaneous laparoscopic totally extraperitonea repair for concurrent ipsilateral spigelian and indirect inguinal hernia. Surg Laparosc Endosc Percutan Tech 18(4):414-416

18. Leff DR, Hassell J, Sufi P, et al (2009) Emergency and elective laparoscopic repair of spigelian hernias: two case reports and a review of the literature. Surg Laparosc Endos Percutan Tech 19:e152-e155

19. Saber AA, Elgamal MH, Rao AJ, et al (2008) Laparoscopic spigelian hernia repair: the scroll technique. Am Surg 74:108-112 